DOI: 10.2478/linpo-2014-0009

\title{
Factors influencing the pronunciation of adult speakers of a foreign language
}

\author{
Emilia Szalkowska-Kim \\ Department of Polish Studies, Hankuk University of Foreign Studies, \\ unde_venis@hotmail.com
}

\begin{abstract}
Emilia Szalkowska-Kim. Factors influencing the pronunciation of adult speakers of a foreign language. The Poznań Society for the Advancement of the Arts and Sciences. PL ISSN 0079-4740, ISBN 978-83-7654-384-0, pp. 141-158
\end{abstract}

The present paper is an overview of selected investigations into acquisition of second language phonology (L2). ${ }^{1}$ It describes L2 phonology researchers' attempts to determine the number, quantity, quality and roles of the factors which shape the pronunciation of L2 adult speakers, i.e. what is the influence of native language limitation, how the L2 phonology acquisition is governed by universal linguistic features, and whether adults use the same processes in acquiring the L2 that are used by children when they acquire their first language. This article will describe a number of longstanding phonetic and phonological projects whose aim was to discover patterns in the improvement of pronunciation in a second language (see research by Archibald, Broselow, Eckman, Flege, Hancin-Bhatt, Major and Weinberger, published in numerous compilations). It strives to explain the universal stages in the development of second language phonology. The main goal of the research is to assess the grammatical knowledge of the L2 learner, i.e. their competence in their interlanguage. The analyses show typological disproportions and universality of the strategies applied by the speakers in the target language. A few important hypotheses have been established (see below for their description), but it is important to note that most of the results verifying these hypotheses concern the acquisition of the English language, with a variable being the "input" languages of the speakers. Although this unilateral focus of the research projects reflects the expansion of the English language as the lingua franca of modern times, it might severely limit understanding of the important and interesting aspects of second language acquisition which structurally do not apply to that language, and are consequently overlooked.

Keywords: second language acquisition, second language phonology, pronunciation

\section{Influence of L1 on L2 phonology}

The analyses conducted in the 1950s and 1960s concentrated on predicting and explaining the errors in L2 pronunciation through the L1 of the learner (see for example Contrastive Analysis Hypothesis, CAH, Lado 1957; see Eckman, website). Contrastive research was

${ }^{1}$ Second language is understood here to mean every linguistic system acquired after the native language (regardless of which foreign language it is for the speaker) and not (in the strict sense) as in some countries, as an 
mainly conducted through the juxtaposition and comparison of phonemes and their allophones' distribution in the analysed languages. According to Lado (1957), the most difficult part for the L2 learner is ascribing the allophones of one phoneme in L1 to separate phonemes of the acquired language; in other words, production of allophones of one's native language in new contexts and ceasing to produce the L1 allophones in the contexts known from the L1. The learner's success and correct pronunciation in L2 can be largely ascribed to their ability to reject the associations between the phonological aspects of L1 and L2 and therefore minimize the transfer of phonological features from one language to another. Eckman et al. (2003) observed that the "disjunction" of the L1 allophones into separate phonemes in the target language proceeds in stages. First speakers find it easier to control the contrasts inside a morpheme (tautomorphemically) and only later on the boundary of two morphemes (heteromorphemically).

On the other hand, Wode (1976) observed that certain requirements must be met (at least in the L2 learner's mind) about the similarity concerning certain structures in L1 and L2 in order for the L1 to influence the second language acquisition (see Eckman www.uwm. edu/ rlschlei/pdfs/L2.phonology.SOA.rev.pdf). This rule was called the Crucial Similarity Measure (CSM). On the other hand, Wode also refers to the various ways of defining the criteria of similarity between the segments in L1 and L2. Some of those criteria concern acoustics, perception, articulation, and even orthography, all of which cause the researchers to adopt different approaches in their own research. Because of that, the Japanese liquid consonant will be considered more akin to the English /r/ by some and to the English consonant /1/ by others (Major 2001: 39).

Flege $(1987,1995,2003)$ focused on the role of phonetic similarity and perceptionproduction relations in L2 phonology acquisition. ${ }^{2}$ His Speech Learning Model is a result of over 15 years of intensive instrumental phonetic research. It has many proponents and is widely applied (see for example the confirmation of Flege's hypotheses by Paradowska (2002) for the perception and production of Korean consonants by Poles). Flege's model assumes a phonetic level of analysis. It defines a segment as a positional variant. According to it, only phonetic categories are itemized in the long-term memory as abstract, languagespecific representations of speech sounds. An important term is equivalence classification. It assumes no additional phonetic category for an L2 consonant if it is equivalent or similar to one known from the L1, because the two are perceived as the same. The learners use sub-

official language present next to a speaker's native language. The term interlanguage was used for the first time by Selinker during the 2nd International Congress of Applied Linguistics in 1969 to describe a learner's competence being the outcome of the competence in the native and target languages, cf. Szulc 1997. In this article the terms L1 and L2 will correspond respectively to the native language (primary language, first language, mother language) and the learner's foreign language (target language, second language).

2 It should also be noted that in the present article it was consciously decided not to include a broad overview of various experimental research concerned with the connection between perception and sound production in L2 and addressing the following issues: Does correct production precede correct perception in the process of L2 acquisition or is it the other way around? Can speakers correctly pronounce sounds which are not correctly perceived or is correct perception a requirement for correct pronunciation? Much evidence so far has substantiated both hypotheses, because the perception-production relation may depend on, for example, the type of sounds, their acoustical and perceptual correlates, the influence of contrasts, etc. It must be noted that the answers to these questions have major practical implications regarding suitable methodologies for teaching pronunciation. 
stitutions from L1 and the process of improving pronunciation is compromised. Only a difference that is perceived leads to a difference in production. New sounds (different to the ones known from L1) are easier to be acquired because the speaker perceives the difference in their sound realization and, therefore, establishes new phonetic categories for them more quickly, be it consciously or subconsciously. Flege shows the importance of the speaker's age, differences between individual speakers as well as the different nationalities of speakers in acquisition of the acceptable pronunciation of a given language. For example, a speaker of a nationality whose phonetic inventory notably differs from the target language's finds phonetic contrasts of the target language easier to learn than people whose native language includes similar (but not identical) phonetic contrasts. Moreover, if linguistic errors have already become fossilized, it will be easier to rectify them if they concern foreign features. A Korean speaking Polish, for example, would more easily rectify an error such as $/ \mathrm{v} / \rightarrow / \mathrm{b} /$ (as neither of the phonemes exist in Korean) than $/ \mathrm{r} / \rightarrow / 1 /$ which are considered allophones of the same phoneme in the Korean language. ${ }^{3}$

A viewpoint that differs significantly from Flege's Language Learning Model is represented by Jacewicz (1999). She claims that in second language acquisition the speakers' concentration on expressing lexical contrasts in L2 is a greater driving power than detecting phonetic contrasts between L1 and L2 on the level of language performance. Jacewicz put forward a Lexical Contrast Hypothesis which states that in the process of creating an interlanguage phonology, language acquirers aim mainly at detection and expression of contrasts and relations between L2 segments in the mental lexicon. Of course, the acquisition of contrasts on the lexical level takes place through the processing of information that comes from the phonetic level. The hypothesis deserves further verification, because it suggests that an organizational unit of syllable or word size can be considered a unit of identification between languages.

\section{Developmental processes}

Comparative work intended to confirm Lado's hypothesis (CAH) were conducted over many years and led to its moderation or partial rejection. ${ }^{4}$ It turned out that $\mathrm{CAH}$ could not embrace all of the phenomena appearing in the phonology of the interlanguage, because some of them should be attributed to developmental processes that reflect the formation of a new linguistic system, similar to those which accompany L1 acquisition (cf. the developmental model - Flege \& Davidian 1984). It was found that some mistakes which cannot be attributed to L1 transfer can be explained on the basis of a speaker's motoric difficulties in

3 Another model for the perception of non-native segmental categories was proposed by Best (cf. Perceptual Assimilation Model, PAM, e.g. 1995). It was created based on a number of perception research studies of monolingual speakers who discriminate sounds not belonging to their native language. Although this research does not refer to the context of L2 acquisition or L2 segment production, it is used in discussions concerning the perception of the acquired language.

4 It is worth noticing that although Lado's hypothesis did not survive in its strong version, we owe to it the discovery that not only differences but also similarities between the L1 and L2 are the source of errors in the interlanguage. 
articulation. L2 learners, for example, while acquiring the fricatives, use substitution strategies similar to strategies used by children who acquire L1. For instance, Russians who speak English frequently substitute the interdental consonant $[\theta]$ with [t] (cf. Lombardi 2003). The developmental model of language acquisition anticipates that there may exist some universal, linguistically persistent hierarchy of phonemic substitutions encompassing their order and character.

A theory has been proposed which describes interactions between transfer and evolutional factors (cf. Ontogeny Model - Major 1987, 2000). This theory states that the frequency of the occurrence of substitutions in L2 which is attributed to transfer from a native language decreases with time, i.e. with a student's progress. The frequency of the occurrence of developmental substitutions, however, at first increases, but later on it decreases. What is more, changes in the number and quality of substitutions behave in the same way with an increase in the level of formality of a communicational situation.

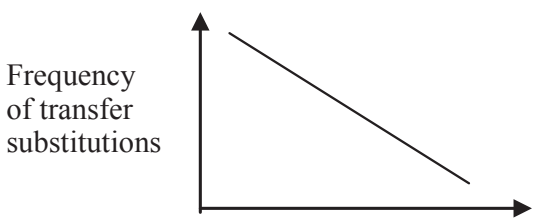

Time / formality

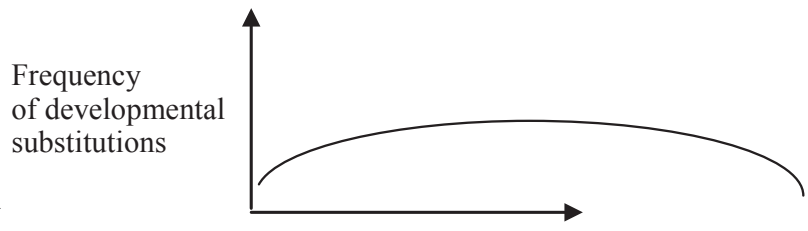

Time / formality

Figure 1: Ontogeny Model (Major 1987, after Major 2001)

\section{Influence of universals on L2 phonology}

The influence of universal rules on L2 phonology acquisition is the second main domain of analysis. The issue, which to a large extent lies at the foundation of research in L2 phonology, is a wish to establish to what extent the mental grammar of an interlanguage (IL) is similar to grammars of native, natural languages. It needs to be emphasized that the phonology of an interlanguage is regarded as equal and equally abstractive as phonologies of native and target languages, and not merely as an "imitation" of the phonology of an acquired language (cf. Interlanguage Hypothesis, Selinker 1972, after Lakshmanan \& Selinker 2001). In other words, despite the fact that the learner's language can be treated as a certain version of a target language, it must be given its own, independent status. The implications are of great interest to phonologists. Certain patterns, e.g. segmental units or their combinations that occur in L2, cannot be attributed to transfer from a native language or to acquired structures from a target language, as the two "input" languages do not exhibit such patterns. For example, Altenberg and Vago (1983) noted that Hungarians, while speaking English, regularly devoice obstruents in word-final position, even though Hungarian displays contrast in obstruent voicing in that position. On the other hand, these regularities, e.g. devoicing in word-final position, occur in many other natural languages and can be justified by universal rules of markedness.

Many approaches and definitions can be related to the concept of markedness. This theory stems from the Prague school. Originally, it was a distinction between two margin- 
ally distinctive segments (phonemes): marked and unmarked, emphasizing that such binary opposition does not have the character of two equal poles, but that one of them is privileged. The theory of markedness was transferred to the field of other linguistic representations (cf. for example the unmarkedness of open syllables, indicative mood or present tense). A number of criteria were established to determine the unmarked (privileged) part of an opposition, e.g.:

- it is more widely distributed in the languages of the world (cf. Greenberg 1978, typological markedness);

- it has a greater frequency of occurrence within a given language;

- it appears in a neutralized position (segment);

- it is acquired earlier by children in their L1;

- it is more stable from a diachronic point of view.

In each case, the marked part has a feature that the unmarked one lacks (this feature is the basis of the privative opposition between them). Apart from that, its presence in a given language implicates the existence of its unmarked counterpart in the given language as well, which is viewed as simpler, more basic and natural. For instance, if a given language has syllables of CVC type, it also has syllables of CV type. However, taking into consideration the great diversity among world languages, creating an absolute hierarchy of markedness is almost an impossible task to accomplish. As such, most often it is the general universal tendencies and preferences which are referred to when discussing the theory.

Final devoicing, given as an example above, can be treated as a preference for the emergence of unmarked structures in L2. The use of universal rules to explain regular patterns in an interlanguage, unjustified by the differences or similarities between L1 and L2, led Eckman (1991) to a formal formularization of the Structural Conformity Hypothesis. It states that universal generalizations are also valid for interlanguages. The fact that the learners cope better with less marked structures, as opposed to structures that are more marked typologically, also seems to support this hypothesis.

Eckman is also the author of an earlier hypothesis on the influence of differences in markedness between L1 and L2 on learning L2 (Markedness Differential Hypothesis, MDH, Eckman 1971), which is an extension of or - as Major (2001) emphasizes - a rescue for the contrastive analysis hypothesis (CAH). MDH predicts that difficulties which an L2 learner may encounter can be determined on the basis of systematic comparison between L1 and L2 grammars and the relation of definiteness in universal grammar:

(1) Difficulties will be posed for an L2 learner by those aspects of a target language that are different from the native language and are more marked than in the native language.

(2) The areas of a target language which are different in L1, but are not more marked than in L1, will not pose difficulties.

From a different point of view, the less marked is a phonetic or phonological structure in the native language, the more often it will be transferred to the phonological system of an acquired language. Unmarked phonological characteristics of L1 are acquired at a very 
early stage, and then strongly consolidated, and are therefore transferred to L2 easily. It is this process which is responsible for the so-called foreign accent of a speaker. ${ }^{5}$

Numerous studies have confirmed the predictions of MDH that relative degree of difficulty corresponds to relative degree of typological markedness. What is more, this hypothesis also reflects the "orientation" of linguistic difficulties. For example, in language X, voicing is contrastive in word-final position, whereas in language $\mathrm{Y}$ it is not. Two speakers, one a native speaker of language $\mathrm{X}$, and the other of language $\mathrm{Y}$, are teaching their languages to each other. The process of second language acquisition will be, most probably, asymmetrical: the native Y speaker will have difficulties with the acquisition of marked voice in word-final position in language $\mathrm{X}$, whereas final devoicing will be less difficult for the native X speaker.

Drawing heavily on the data collected by Kim concerning the acquisition of English language phonology by Koreans, Major suggested a hypothesis which combines observations concerning markedness of linguistic structures with hypotheses included in Flege's Speech Learning Model (Major and Kim 1996; Similarity Differential Rate Hypothesis, after Major 2001). According to this hypothesis, dissimilar linguistic phenomena (structures) are acquired faster than similar ones, and the mediating factor is their markedness, which hinders the acquisition process. Major (2001) claims that the definition of "difficulty" or "easiness", used so often in the description of the L2 phonology acquisition, are not proper or sufficient terms. We can say that some segment (or structure) $x$ is easier than $y$ because the results of research show a higher percentage of correct realizations. They may not, however, show the same result at the next or final stage of language acquisition, when the same speakers are shown to perform $y$ with greater accuracy than $x$. Because of this, Major favours research that is spread over time and studies the L2 pronunciation at different levels of proficiency, as well as determination of the pace at which respective segments or phonological structures are acquired (cf. for example Hayes, http://www.u.arizona.edu/ rhayes/). In other words, according to Major, hypotheses would be more valuable if they were able to predict the pace of acquisition, and not its difficulty, as the former factor is a better indicator of the progress that an L2 learner makes.

\section{Major's Ontogeny Phylogeny Model}

Major also worked for many years on verifying and modifying the abovementioned Ontogeny Model (Major 1987). Consequently it evolved into the Ontogeny Phylogeny Model (Major 2001). This theory perceives the grammar of an interlanguage (IL) as a system consisting of three components: the native language (L1), the target language (L2), and universals (U), all of which interact with each other. It tries to establish how the input of the aforementioned language components changes with its development in time. This is an interesting approach, because previous theories did not try for example to analyse the role and proportions of linguistic universals that were not a part of L1 or L2 with regard to the

5 A foreign accent is usually understood as the inability of non-native users of a language to speak it with such phonetic precision that the native speakers of the language perceive its pronunciation as native. Today we may also consider the "perceived foreign accent" which refers to the difficulties in the fluent acquisition of those perceptual contrasts in L2 which do not function in L1 (cf. e.g. McAllister et al. 1999). 
role of L1 in the L2 acquisition. The model, which is supposed to provide very general statements, points to four kinds of results in the development of an interlanguage, and predicts their further course (cf. Major 2001):

1. In the chronological development of IL:

a) the contribution of L2 increases,

b) the contribution of L1 decreases,

c) the contribution of $U$ increases, and then decreases.

2. As regards marked phenomena, in IL:

a) the contribution of L2 increases slowly,

b) the contribution of L1 decreases, and then decreases slowly,

c) the contribution of $U$ increases rapidly, and then decreases slowly.

\#The role of $\mathrm{U}$ is more important than L1, in comparison with less marked phenomena.

3. As regards similar phenomena in IL:

a) the contribution of L2 increases slowly,

b) the contribution of L1 decreases slowly,

c) the contribution of $U$ increases slowly, and then decreases slowly.

\# The role of $\mathrm{L} 1$ is more important than $\mathrm{U}$, in comparison with less similar phenomena.

4. As the style becomes increasingly formal:

a) the contribution of $\mathrm{L} 2$ increases,

b) the contribution of L1 increases,

c) the contribution of $U$ increases, and then decreases.

Major (2001) claims that the abovementioned general rules characterize both single as well as multiple L2 acquisition, loss of L1, and mono- and bilingual language acquisition, and they apply both to individuals and to groups and generations of speakers.

There are also further proposals within universal grammar, as understood by Chomsky as a grammar that consists of rules and parameters (cf. for example Desrochers 1998). The rules are a common part of all languages, whereas the diversification between many languages stems from the different setting of their parameters with respect to these universals. Such a parameter, with its value dependent on the given language, is, for instance, the index of minimal distance in respect of sonority of neighbouring segments (Minimal Sonority Distance, cf. Broselow \& Finer 1991), which characterizes diversity among languages with regard to the consonant clusters that are allowed in them, e.g. in syllabic onset.

\section{L2 phonology acquisition according to Optimality Theory}

Many general approaches to phonology allow one to conceptualize the acquisition of the phonology of a second language in its different aspects, e.g. phonemics, theories of distinctive features, syllabification theories, natural phonology (cf. e.g. Dziubalska-Kołaczyk 1990; 1999; 2002), autosegmental phonology (cf. e.g. Goldsmith 1990), geometry of features (cf. Clements and Hume 1996), phonology of rules and parameters (cf. e.g. Broselow 
\& Finer 1991). On the other hand, examination of the acquisition of pronunciation in L2 contributes to the understanding of phonology. In this paper, only the Optimality Theory formulated by Prince and Smolensky and its main assumptions will be presented (Optimality Theory, OT 1993; cf. Rutgers Optimality Archive, ROA). This choice has been made for several reasons: (1) it is one of the newer phonological approaches; (2) descriptions of the phonology of the Polish language in accordance with this theory are scarce (cf. e.g. Gąsiorowski 1999); and (3) this theory is very promising from the point of view of linguistic typology and second language phonology, because explicitly formulated universal rules of markedness are an integral part of it. For instance, Broselow et al. (1998) showed that within OT there can be investigated universals of all types, e.g. phonotactic, segmental and suprasegmental properties.

Moreover, it is a somewhat radical and non-derivational theory, as it replaces a set of ordered rules which connect underlying forms with their surface phonetic realizations (cf. generative phonology), with the grammar of language, seen as a hierarchy of universal constraints (rules, principles). It is also a theory of linguistic typology, because it presupposes that every ranking of universal constraints should provide a certain grammar of some language, and such a grammar of a language should be in accordance with a plausible ranking of constraints.

The constraints are universal criteria of structural (phonotactic) correctness, they have the form of absolute (positive or negative) rules that refer to surface forms (phonetic realizations), and languages differ from each other with regard to the ways in which they apply those criteria, i.e. what hierarchy they have. Unlike non-linear phonologies, Optimality Theory does not concentrate on features which are common to different languages, but on the ways languages differ from each other, i.e. how their arrangements (rankings) of universal constraints differ. The constraints are not independent, and conflict with one other. Such a conflict can only be resolved by a violation of some constraints, which is linguistically specific. No language and no utterance fulfil all universal criteria of correctness of structure. All constraints are prone to violations. They are formulated in a positive, negative, or an implicational form. An optimal output form, i.e. correct from the point of view of a given language, is chosen from a set of phonetic forms that are logically plausible, and it is compatible with the constraints that are ranked highest in the grammar of a given language. For example, a constraint that prohibits the occurrence of consonant clusters in a syllable's coda is ranked higher in the hierarchy of Korean than in that of Polish, which does allow such clusters.

Constraints can be divided into two categories: markedness constraints and faithfulness constraints. The first are also known as structural constraints, and they are responsible for the universal preferences for certain linguistic structures, e.g. for oral vowels, syllables with onsets, voiceless obstruents, etc. Their role is to ensure that an utterance can be articulated and/or perceived more easily. ${ }^{6}$ They can prompt epenthesis, for example. Faithfulness constraints are responsible for maintaining the input segments intact. The output (phonetic) form should be as close to the input (underlying) form as possible - which is key to the attempt to maintain the comprehension of the utterance and its contrasts with other utterances. Faithfulness constraints prohibit reductions, epentheses, changes in segments, etc.

${ }^{6}$ Some researchers propose them as being functionally and phonetically motivated (cf. Boersma 1998). 
McCarthy and Prince (1994) refer to mutual relations between the mental pattern and the output forms not as faithfulness constraints but as correspondence constraints. This term seems to be more satisfactory if our aim is to underline the fact that the ontological status of both forms, the underlying and the phonetic, is different.

The presence or lack of a given marked structure in a language depends on the ranking of the markedness constraints in relation to the faithfulness constraints. If faithfulness $(F)$ dominates over markedness $(M)$, written $\mathrm{F}>>\mathrm{M}$, then a marked structure emerges. However, in the opposite case, when the markedness constraints dominate over faithfulness constraints $(\mathrm{M}>\mathrm{F})$, these marked surface realizations are rejected.

To sum up, according to OT, grammar functions in the following way. Underlying forms are imprinted on surface forms, but there is no sequence of ordered principles that would generate output realizations. It might be said that this equals one-step derivation - for every input the grammar chooses one optimal output from an infinite set of candidates. These potential surface realizations are produced by the function known as the generator (GEN). Each candidate violates different sets of constraints, in other words, it fulfils the requirements of the constraint ranking in different ways. All constraints present in the grammars of natural languages are parts of the constraint set (CON), i.e. the universal inventory of constraints. Within the framework of the Optimality Theory it has most often been assumed that these constraints are inborn and that the phonology of a given language is acquired by establishing a ranking (hierarchy) of constraints. It is also inferred that some, if not all, constraints have a purely formal character without being directly motivated by phonology. ${ }^{7}$ The grammar possesses an evaluating function (EVAL) which chooses the optimal candidate, i.e. the form which is best adjusted to the general hierarchy of constraints in the given language. This hierarchy has the following form: $\mathrm{CON}_{1}>>\mathrm{CON}_{2}>>_{\ldots}>>\mathrm{CON}_{n}$. It is permissible and acceptable for the winning surface form to violate constraints, as it can violate the principles which are lower in the ranking. A realization wins when it fulfils the highestranking constraint. Lower-ranking constraints are insignificant - their violation does not call into question the winning candidate's grammaticality. On the other hand, a given candidate, and thus the potential surface realization of a morpheme or a word, is automatically rejected if it violates high-ranking constraints, even though it might fulfil all of the constraints of a lower order. Major changes in surface forms, e.g. produced by an L2 speaker, stem from the simultaneous violation of many constraints.

The evaluation of the phonetic surface forms via an ordered set of constraints is presented in the following tableau as a simple constraint interaction scheme:

\begin{tabular}{lll}
\hline /input form/ & $\mathrm{CON}_{1}$ & $\mathrm{CON}_{2}$ \\
\hline candidate $_{1]}$ & $* !$ & \\
$\sigma_{\left[\text {candidate }_{2]}\right.}$ & & $*$ \\
\hline
\end{tabular}

Figure 2: An example tableau of constraints, $\mathrm{CON}_{1}>>\mathrm{CON}_{2}$

${ }^{7}$ Boersma (1998) represents the opposite view. He believes that the constraints are not inborn, but are a result of universal articulatory and perceptual factors which are active during the process of language acquisition. The universal nature of these cognitive and phonetic factors is responsible for the existence of similar constraints in different languages. 
The notation conventions are as follows:

- constraints are typed in descending order (from the most important down to the least important);

- their violations are marked with '*';

- the crucial (fatal) violation, i.e. that which eliminates a given candidate altogether, is given the symbol '!';

- the optimal (winning) output form is denoted by the symbol ' $\checkmark$;

- grey areas indicate that the given constraint does not influence the fate of the candidate; the cells of the losing candidates are shaded in after their fatal violation, while the winning candidate's cell is shaded once it has no other rivals.

The table normally contains only those constraints that are relevant to the given language. It should be noted that a finite set of universal constraints, as yet, has not been created. In order to develop a correct hierarchy of such constraints, the analysis of data using such a formal apparatus would require a rather broad knowledge of both the interactions between the constraints and the analysed phonological system itself. The table also does not include all possible candidates, the number of which is theoretically limitless, but contains only those realizations that are structurally similar to an optimal realization.

According to Optimality Theory, building language competence in one's native language, i.e. acquisition of the grammar of a given language by a child in their L1, is achieved by finding the correct order of universal constraints, optimal for the given language (cf. Tesar and Smolensky 1998). The theory does account for individual variation. At first the hierarchy of constraints differs for every language learner, but as the learning process progresses, reranking takes place and the produced output becomes more and more correct. This is achieved thanks to input forms. Adult users of the same language, or, in specific terms, the same dialect, possess an identical hierarchy of constraints. At first it was assumed that the attainment of a correct order of universal rules specific to a given language and the phonological development of its users is achieved not through the promotion of rules but through their demotion (cf. Tesar and Smolensky 1998). It might happen that, due to the abstract mechanisms of the evaluator function (EVAL) and its evaluation of an L2 learner's speech, no candidate will be chosen as identical to the target phonetic form which a native speaker of the language would have produced. Then the language system of that learner should be able to identify which constraint was responsible. Apparently it was the highest ranking constraint which was fatally violated (*!). If this is demoted in the constraint ranking in the right way, then the next realization of this word will be either identical or closer to the correct pronunciation. Of course, other rules may be too high in the constraint ranking as well, thus prompting other errors along the word's linear structure. If such is the case, the pronunciation learning process should incorporate constraint demotion until correct pronunciation is achieved. It has been said that an opposite mechanism, i.e. promoting constraints, would be difficult to prove, as determining which of the low-ranking universal rules should be ranked higher is a daunting task. The promotion of incorrect constraints would result in a departure from the optimal hierarchy for language acquisition ${ }^{8}$. Nowadays a number of scholars propose that the process of phonology acquisition by children should be understood

${ }^{8}$ Unfortunately, the constraint promotion theory cannot explain, for example, the stages of regression in language acquisition. 
as one that goes in the opposition direction, i.e. promoting faithfulness in the process of acquiring one's grammar and bringing it closer to the grammar of adult users and the correct pronunciation of marked linguistic structures (cf. Gnanadesikan 2004).

Interlanguages are natural languages, so acquisition of their phonology should proceed similarly to the way in which the phonology of a native language is acquired. The main difference between these two types of languages is that L1 acquisition emerges from the constraint hierarchy in which principles of markedness dominate over the rules of faithfulness (cf. e.g. Gnanadesikan 2004). Principles of markedness prevent the appearance of marked features, segments or linguistic structures of greater complexity and, also, provide restrictions on the grammatical system. L2 acquisition, however, most probably commences with the constraint ranking that is already established for the L1. In both cases, though, markedness constraints must be gradually demoted in relation to faithfulness constraints, so that the language user is able to produce more and more marked utterances. Faithfulness constraints dominate in adult learners of the acquired language. This stems from the necessity of creating a sufficient number of contrasts in the given language so that a large lexicon can be developed.

One of the characteristic phonetic phenomena which could be described thanks to the apparatus of the Optimality Theory is "the emergence of the unmarked". That is, for example, obstruent omission in syllable-final position, the lack of complex onset, or finalobstruent devoicing, both in the phonologies of the L1 and of the interlanguage (cf. e.g. McCarthy \& Prince 1994). If the dominating faithfulness constraints conflict with the lowerranking markedness constraints, then the effects of the markedness constraints will remain unnoticed. On the other hand, it is important to keep in mind that low-ranking constraints, most often principles of markedness, are parts of a language's grammar. In some cases they might be decisive in evaluating candidates. When there is a "tie" between two high-ranking faithfulness constraints which are also contradictory, then the lower-ranking markedness constraints choose the unmarked structure as the optimal surface form. The emergence of unmarked structures in the interlanguage can be also explained through the transfer of L1 markedness principles which are too high in the hierarchy of constraints and have not yet been demoted in the process of L2 acquisition. Broselow, Chen and Wang (1998) give examples of such "emergence of the unmarked". They list strategies implemented by native speakers of Mandarin dialects of Chinese that simplify coda obstruents in the English language. In Mandarin the coda of the syllable may be comprised only of non-syllabic vowels (glides), $\backslash n \backslash$ and $\backslash \eta \backslash$. The majority of users of Mandarin, when learning English, experience the same coda modification strategies. These include vowel epenthesis and reduction (aiming at open syllables) as well as obstruent devoicing, where epenthesis is used mainly in monosyllabic words and devoicing in disyllabic words. To sum up, language acquisition proceeds from the unmarked to the more marked syllable structure.

The Optimality Theory can potentially explain the emergence of certain structures in the phonology of the interlanguage which are independent and different from those known in the L1 and L2, but which can be observed in other natural languages. The appearance of these new structures is ascribed to low-ranking principles which are not visible in those hierarchies that are specific to both the native and the target language, but still attain a high position in the constraint ranking of the interlanguage (cf. Broselow et al. 1998). This phenom- 
enon occurs when, for example, the phonotactics of the given first language do not allow for obstruents in word final position, while the target language contrasts between voiced and voiceless obstruents in that position. In such a case, speakers of the interlanguage devoice word-final obstruents, which means that unmarked segments appear in the final position. Such a phenomenon has been observed in the speech of, for example, L2 English speakers whose L1 is a language from the Southern Bantu group, such as Soto, Nguni and Zulu (cf. e.g. Grijzenhout and Rooy, website).

Another example of the emergence of the unmarked is the breaking of consonant clusters in syllable onsets via epenthesis if the first language does not allow such clusters (cf. for example the breaking of consonant clusters such as /obstruent+sonorant/ in the onset of words borrowed into Zulu from English; Grijzenhout and Rooy, website). In this case, for the Zulu language it is the markedness constraint that is higher in the hierarchy of universal principles than the principles of faithfulness.

By way of a summary, a catalogue of "repair strategies" can be created to illustrate how learners cope with the phonology of L2 from the standpoint of their native language and universal phonological principles. These strategies are incorporated mostly subconsciously in both the perception and the production of utterances in the L2. All of the following phonological processes take place in the interlanguage as well as in other natural languages: epentheses, reductions, metatheses, and segment quality modifications (modifications of one or two features, e.g. substitutions, neutralizations, assimilations, dissimilations). All of them are a core part of any phonetic system. Some of them strive to minimize the motoric effort (articulatory effort) of the speaker, while others stem from the need to maximize contrasts, which in turn improves perception. This article discusses these processes in detail for the interlanguage known as $\mathrm{K}_{\mathrm{OR}} \mathrm{P}_{\mathrm{OL}}$. Its aim is to show the hierarchy of strategies implemented by native Korean speakers to repair the "invalid structures" present in acquiring Polish segments, and particularly in acquiring consonant clusters and certain consonantal contrasts in the onset and the word-final and syllable-final positions. Indirectly, the research is also intended to demonstrate the relevancy of the hypotheses discussed at the beginning of the paper.

Some of the strategies dealing with new segments or structures in the target language are limited only to certain stages of the acquisition of its phonology, and are incorporated by language speakers consciously. Omission and hypercorrection may serve as examples. A natural phenomenon is the omission of those features of correct pronunciations which are problematic. Speakers implementing this strategy may even go as far as omitting certain words which contain sounds or clusters of sounds which they find difficult to pronounce. For example, Korean speakers of Polish may in certain instances avoid words with [ $\widehat{\mathrm{d}}]$ ], [v] or $[z]$, as they are aware that they might pronounce them incorrectly.

The strategy of hypercorrection is rather surprising, as a sound correct only in certain L2 contexts is replaced by another, but no L1 transfer is viable here. This contrast is overly extended to new vocabulary. For example, some Korean speakers of Polish enter a stage in which they pronounce the sound [f] instead of [p] or [v] instead of [b]:

1) Polish

$\mathrm{ka}[\mathrm{p}] \mathrm{ka} \rightarrow \mathrm{ka}[\mathrm{f}] \mathrm{ka}$

'a droplet' 
2) Polish

$$
\begin{aligned}
& \mathrm{ko}[\mathrm{b}] \mathrm{ra} \rightarrow \mathrm{ko}[\mathrm{v}] \mathrm{ra} \\
& \text { 'cobra' }
\end{aligned}
$$

This phenomenon cannot be ascribed either to negative transfer from Korean, as the phonemes /f/ and /v/ are not present in Korean, or to any universal drive towards unmarkedness, because, for example, the phoneme /f/ is typologically more marked than $/ \mathrm{p} / \mathrm{is}$.

Although very promising for the purpose of explaining the phonology of the interlanguage, the Optimality Theory still does not offer a satisfying answer to the issue of the hypercorrection strategy discussed above. It does not account for the emergence of the marked instead of the unmarked, where the first does not stem from the faithfulness principle in L2 nor from L1 transfer. The incapability of any phonological theory to explain certain phenomenon which it should be able to account for can be a problem - but it is a serious problem only when certain issues cannot in any way be explained within the theory's framework. The Optimality Theory is still being developed. Only time will tell its real explanatory potential.

Eckman et al. (2003) state that hypercorrection occurs at the third stage of acquiring an L2 phonology, after the beginning stage, which is characterized by the lack of perceivable contrast typical of the L2, and after the second stage which develops sensitivity to the contextual environments of the L2. Such hypercorrection may be a result of previous errors, stemming from L1 transfer, having been recognized and acknowledged. This makes the speaker more sensitive to the production of new utterances in L2 and makes the speaker realize that L1 patterns are not valid in L2. This causes the rejection of the principle or constraint that was the source of the errors in the past. It is not until the last stage occurs that a new word becomes correctly lexicalized and production strategies which were contradictory, i.e. which had their source in interference and hypercorrection, are now neutralized. As a result the word is pronounced correctly.

\section{Influence of orthography on L2 pronunciation}

The last strategy that will be discussed here is over-reliance on orthography, in particular by speakers whose native language's orthography is very phonemic, i.e. the conversion ratio between graphemes and phonemes is $1: 1$. If the speaker interprets the pronunciation of the target language through its orthography, and its principles of conversion are more complex than in the speaker's native language, then segmental errors will occur even though the speaker would be able to pronounce the correct sounds in the given contexts. This can be exemplified by the way Korean speakers of Polish pronounce words in which regressive devoicing or final-obstruent devoicing occurs:

1) Polish

$$
\begin{aligned}
& \text { wtorek }[\mathrm{ft}] \text { orek } \rightarrow \quad[\mathrm{vt}] \text { orek } \\
& \text { 'TueSday' }
\end{aligned}
$$

2) Polish

$$
\begin{aligned}
& \text { wsad } \\
& \text { 'batch' }
\end{aligned},[\mathrm{fs}] \mathrm{a}[\mathrm{t}] \rightarrow \quad[\mathrm{vs}] \mathrm{tat} \text { or }[\mathrm{vs}] \mathrm{a}[\mathrm{du}] .
$$




\section{Influence of extralinguistic factors on L2 phonology acquisition}

Apart from the universal and developmental factors, L1 transfer included, which have been discussed above, there are also other extralinguistic factors and strategies which influence L2 phonology acquisition. The discrepancy in learning effectiveness in language learners can be caused by the following individual and social factors:

- personality (cf. intro- and extraversion and other psychological factors);

- motivation (cf. e.g. Piske et al. 2001):

- instrumental: achieving specific aims such as finding a job or passing an exam;

- integrative: becoming a part of the society and culture associated with native speakers of the given language;

- individual factors and auditory and articulatory skills (cf. e.g. musicality);

- risk-taking;

- level of socialization;

- acceptance into society, distance, pressure;

- feelings of identity (also linguistic identity, cf. being forced into acquiring an L2, accent as a symbol of ethnicity and psycholinguistic distinctiveness);

- membership of a social group or class;

- age (cf. the critical age hypothesis, Lennenberg 1967, and sensitive period hypothesis, Bornstein 1989; cf. Flege et al. 1995; 1999; Birdsong \& Molis 2001; Lin et al. 2004);

- sex (cf. e.g. Yang 1996; Piske et al. 2001);

- brain hemisphere specialization;

- experience in language usage, period of stay within an environment using the L2 as the native language (cf. e.g. Flege et al. 1997; McAllister 2001);

- education;

- conditions revolving around L2 acquisition: use of the language in class or in real communicational situations in its natural environment, influence of the level of multilingualism in the society;

- dialect or language prestige;

- individual learning strategies: training;

- individual styles and cognitive skills, e.g. acquiring mainly specific areas of the language (cf. e.g. Robinson 2001);

- type of writing, alphabet (cf. e.g. Tan et al. 2003; Akamatsu 2003);

- schooling system; methods of language teaching (cf. e.g. Koren 1995; Jones 1997; Shohamy 2000), the influence of concentrating only on the written side of the language Harklau 2002).

The influence of differences in cognitive skills on L2 acquisition in a variety of language "exposure" situations (i.e. different conditions of psycholinguistic processing) is a subject of scientific study also in domains other than linguistics, e.g. psychology and psychotherapy (cf. e.g. Robinson 2001; Hahne 2001; Pallier et al. 2001; Marsden 2002; Hu 2003; Ellis 2004). Researchers are working on establishing a theoretically-based scale of language pro- 
ficiency based on analysis of how learners of an interactive language employ two factors: (1) cognitive abilities, i.e. for example concentration, long and short term memory, speech processing efficiency; and (2) cognitive processes based on skills, e.g. recognizing patterns and system gaps, working phonological memory efficiency, deep semantic processing, etc.

\section{Data collection and methodological biases}

The variation and discrepancy in levels of pronunciation both in one individual speaker and among many other speakers may be the result of context, e.g. the level of formality of the communicative situation (cf. e.g. Major 1987), or the methods of collecting data for analysis; for example, in laboratory environments elicitation techniques are used. The sum of our knowledge on the nature of competence in the interlanguage is gained indirectly, through the analysis of data on "language production", for example through the analysis of spontaneous speech, experimentally acquired speech, and experimental data concerning auditory production and levels of understanding. Lakshmanan and Selinker (2001) warn about comparative errors in the research of interlanguage, as these errors stem from biases concerning both the native and the target language which may lead to underestimation or overestimation of the learner's language competence. In creating linguistic descriptions of an interlanguage, the focus should be placed on its specific features and its own sense of structure, and it should be viewed only as an approximation or even imitation of the given target language. Whenever possible, the collection of data should be a long-term process, in order to understand all the stages of foreign language acquisition. It is often forgotten in analyses that a portion of the speakers go through a so-called silent period, during which they do not produce any utterances in the L2. This stage still remains under-researched, although it is known that the grammar of the interlanguage develops at the same time as certain aspects of the L2 are acquired passively.

As yet, there are no widely available or commercial data bases containing, for instance, large corpora of L2 speech. By contrast, we can find numerous databases of native language speech, including the speech of children acquiring their first language. This means that research is often based solely on the interpretations of the researchers who collected the data (e.g. speech recordings) for a given interlanguage. We lack independent analysis conducted on the same corpus by several researchers and large-scale intralinguistic comparative research - which could be possible given today's possibilities of data storage and processing. Another obstacle is that researchers themselves in many cases decide arbitrarily to include or exclude some portions of data for the purposes of their analyses. The lack of an agreed methodological basis hinders the production of reliable comparative analyses.

\section{Future research}

How our knowledge on second language acquisition (its phonology included) develops in the future depends on interdisciplinary team research (e.g. linguistic, medical, psychological), the collection of larger corpora of data and the testing and implementation of new linguistic theories (such as Optimality Theory or Feature Geometry) as tools of analysis. 
Also, we should partially abandon one-sided comparative studies comparing English with other world languages, in favour of larger numbers of contrastive studies among the "other" world languages themselves. It would also seem that we underestimate the role of bilingual researchers and scholars employed as language teachers, as well as people who are speakers of the given interlanguage (e.g. university-level students of languages). Incorporating their experiences into the research would provide a real possibility of analysing the structure of the interlanguage in all its stages, from the earliest up to the most advanced.

\section{References}

Akamatsu, Nobuhiko. 2003. The effects of first language orthographic features on second language reading in text. Language Learning 53(2). 207-231.

Altenberg, Evelyn P. \& Vago, Robert M. 1983. Theoretical implications of an error analysis of second language phonology production. Language Learning 33. 427-447.

Archibald, John. 2000. Parsing procedures and the question of full access in L2 phonology. New Sounds 2000 Plenary Address. Best 1995.

Birdsong, David. \& Molis, Michelle. 2001. On the evidence for maturational constraints in second-language acquisition. Journal of Memory and Language 44. 235-249.

Boersma, Paul. 1998. Functional phonology. Formalizing the interactions between articulatory \& perceptual drives. Netherlands Graduate School of Linguistics, IFOTT.

Bornstein, Marc. 1989. Sensitive periods in development: Structural characteristics and causal interpretations. Psychological Bulletin 105. 179-197.

Broselow, Ellen. 2001. Stress-epenthesis interactions. Halle \& Vaux (eds.), SUNY Stony Brook.

Broselow, Ellen. \& Chen, S. \& Wang, C. 1998. The emergence of the unmarked. Studies in Second Language Acquisition 20. 261-280.

Broselow, Ellen. \& Finer, D. 1991. Parameter setting in second language phonology and syntax. Second Language Research 7. 35-59.

Clements, G. N. \& Hume, E. 1995. The internal organization of speech sounds. In Goldsmith, (ed.), The Handbook of Phonological Theory, 245-306. Cambridge, Ma.-Oxford: Blackwell Publishers.

Desrochers, Richard. 1998. The role of parameters in phonology: a critical account. Language Sciences 20. 369 397.

Dziubalska-Kołaczyk, Katarzyna. 1990. A theory of second language acquisition within the framework of Natural Phonology. A Polish-English Contrastive Study. Poznań: UAM Press.

Dziubalska-Kołaczyk, Katarzyna. 1999. Fonologia naturalna: podstawy i zastosowania. In Jassem, W. \& Basztura C. \& Demenko, G. \& Jassem, K. (eds.), Speech and Language Technology, vol. 3, 21-32. Poznań: Polish Phonetic Association.

Dziubalska-Kołaczyk, Katarzyna. 2002. Speech is in the ear of the listener: some remarks on the acquisition of second language sounds. In: Selected Papers from the 6th College-wide Conference for Students of Languages, Linguistics, and Literature, Honolulu: University of Hawai'i.

Eckman, Fred R. From phonemic differences to constraint rankings: research on second language phonology: State of the Art. http://www.uwm.edu/ rlschlei/pdfs/ L2.phonology.SOA.rev.pdf.

Eckman, Fred R. \& Elreyes, A. \& Iverson, G. K. 2003. Some principles of second language phonology. Second Language Research 19(3). 169-208.

Ellis, Rod. 2004. The definition and measurement of L2 explicit knowledge. Language Learning 54(2). 227-275. Flege, James Emil. 1981. The phonological basis of foreign accent: A hypothesis. TESOL Quarterly 14. 443-455.

Flege, James Emil. 1987. The production of 'new' and 'similar' phones in a foreign language: evidence for the effect of equivalence classification. Journal of Phonetics 15. 47-65.

Flege, James Emil \& Davidian, R. 1984. Transfer and developmental processes in adult foreign language speech production. Applied Psycholinguistics 5. 323-347.

Flege, James Emil \& Bohn, O.-S. \& Jang, S.-Y. 1997. Effects of experience on non-native speakers' production and perception of English vowels. Journal of Phonetics 25. 437-470. 
Flege, James Emil \& Munro, M. J. \& MacKay, I. R. A. 1995. Effects of age of second-language learning on the production of English consonants. Speech Communication 16. 1-26.

Flege, James Emil \& Schirru, C. \& MacKay, I. R. A. 2003. Interaction between the native and second language phonetic subsystems. Speech Communication 40. 467-491.

Flege, James Emil \& Yeni-Komshian, G. H. \& Liu, S. 1999. Age constraints on second-language acquisition. Journal of Memory and Language 41, 78-104. ID jmla 1999.2638 at http://www.idealibrary.com.

Gąsiorowski, P. 1999. Teoria optymalności: nowe spojrzenie na kompetencję językową. In Jassem, W. \& Basztura, Cz. \& Demenko, G. \& Jassem, K. (eds.), Speech and Language Technology. Vol. 3, 51-57. Poznań: Polish Phonetic Association.

Gnanadesikan, Amalia. 2004. Markedness and faithfulness constraints in child phonology. In Kager, R. \& Pater, J. \& Zonneveld, W. (eds.), Constraints in Phonological Acquisition. Cambridge University Press.

Goldsmith, John. 1990. Autosegmental and Metrical Phonology. Oxford: Blackwell.

Greenberg, J. H. 1978. Universals of human language. Vol. 2. Phonology. Stanford: Stanford University Press.

Grijzenhout, Janet \& van Rooy, Bertus. Second language phonology: Acquisition through gradual constraint demotion. http://www.phil-fak.uni-duesseldorf.de/sfb282/working_papers/Sfb119.pdf.

Hahne, Anja. 2001. What's different in second-language processing? Evidence from event-related brain-potentials. Journal of Psycholinguistic Research 30(3). 251-266.

Hancin-Bhatt, Barbara. 2000. Optimality in second language phonology: codas in Thai ESL. Second Language Research 16(3). 201-232.

Harklau, L. 2002. The role of writing in classroom second language acquisition. Journal of Second Language Writing 11.329-350.

Hayes, Rachel. (http://www.u.arizona.edu/ rhayes/) The perception of novel phoneme contrasts in a second language: a developmental study of native speakers of English learning Japanese Singleton and Geminate Consonant Contrasts. Coyote Papers 12. 28-41. Language in Cognitive Science.

$\mathrm{Hu}, \mathrm{Ch} .-\mathrm{F}$. 2003. Phonological memory, phonological awareness and foreign language word learning. Language Learning 53(3). 429-462.

Jacewicz, Ewa. 1999. Phonological context in the acquisition of second language vowels. (Abstract)

Jones, R. H. 1997. Beyond "listen and repeat": pronunciation teaching materials and theories of second language. System 25(1). 103-112.

Koren, Shira. 1995. Foreign language pronunciation testing: A new approach. System 23(3). 387-400.

Lado, Robert. 1957. Linguistics across cultures: applied linguistics for language teachers. University of Michigan Press.

Lakshmanan, U. \& Selinker, L. 2001. Analysing interlanguage: how do we know what learners know? Second Language Research 17(4). 393-420.

Lenneberg, E. 1967. Biological foundations of language. New York: Wiley.

Lin, H.-L., Chang, H.-W., Cheung, H. 2004. The effect of early English learning on auditory perception of English minimal pairs by Taiwan university students. Journal of Psycholinguistic Research 33(1). 25-49.

Lombardi, Linda. 2003. Second Language data and constraints on Manner: Explaining substitutions for the English interdentals. Second Language Research 19(3). 225-250.

Major, Roy. C. 1987. A model for interlanguage phonology. In Ioup, G. \& Weinberger, S. (ed.), Interlanguage Phonology, 101-124. Rowley: Newbury House Publishers.

Major, Roy. C. 2000. Chronological and stylistic aspects of second language acquisition of consonant clusters. New Sounds 92: 2nd Amsterdam Symposium on the Acquisition of Second Language Speech.

Major, Roy. C. 2001. Foreign accent: the ontogeny and phylogeny of second language phonology. Mahwah-New Jersey-London: Lawrence Erlbaum Associates, Publishers.

Marsden, Heather. 2002. Poverty of the stimulus and UG in Japanese L2 acquisition: a response to Sheen (2000). Durham Working Papers in Linguistics 8. 67-80.

McAllister, R. \& Flege, J.E. \& Piske, T. 1999. Second language comprehension: a discussion of some influencing factors. In The Proceedings of the 9th Annual Conference on the European Second Language Association (EUROSLA 9), Lund, Sweden.

McCarthy, John J. \& Prince, Alan. 1994. The emergence of the unmarked: Optimality in prosodic morphology. NELS Proceedings 24. 333-379.

Pallier, C. \& Colomé, A. \& Sebastian-Gallés, N. 2001. The influence of native-language phonology on lexical access: exemplar-based vs. abstract lexical entries. Psychological Science 2001. 
Paradowska, Anna. 2002. 폴란드의 한국어 모음의 발음과 청취에 대한 실험음성학적 연구. Production and perception of Korean vowels by Polish learners: An experimental phonetic approach. Seoul National University. (Unpublished doctoral thesis)

Piske, T. \& MacKay, I.R.A. \& Flege, J.E. 2001. Factors affecting degree of foreign accent in an L2: a review. Journal of Phonetics 29. 191-215.

Prince, Alan S. \& Smolensky, Paul. 1993. Optimality theory. Constrain interaction in Generative Grammar. ROA Version, $8 / 2002$.

Robinson, Peter. 2001. Individual differences, cognitive abilities, aptitude complexes and learning conditions in second language acquisition. Second Language Research 17(4). 368-392.

Selinker, Larry. 1972. Interlanguage. IRAL 10. 209-231.

Shohamy, Elana. 2000. The relationship between language testing and second language acquisition, revisited. System 28. 541-553.

Tan, L.H. \& Spinks, J.A. \& Feng, C.-M. \& Siok, W.T. \& Perfetti, C.A. \& Xiong, J. \& Fox, P.T. \& Gao, J.H. 2003. Neural systems of second language reading are shaped by native language. Human Brain Mapping 18. $158-166$.

Tesar, Bruce \& Smolensky, Paul. 1998. Learnability in Optimality Theory. Linguistic Inquiry 29. 229-268.

Wode, H. 1976. Developmental sequences in naturalistic second language acquisition. Working Papers on Bilingualism 11. 1-13.

Yang, Byunggon. 1996. A comparative study of American English and Korean vowels produced by male and female speakers. Journal of Phonetics 24. 245-261. 